\title{
LACAN E HEGEL
}

\author{
Ronaldo Torres 1 \\ Instituto de Psiquiatria da Faculdade de Medicina - USP
}

\begin{abstract}
A aproximação de Jacques Lacan à filosofia hegeliana não responde ao acaso. As idéias de tendência concreta e estrutura reacional, presentes em sua Tese de 1932, já indicavam os lugares prévios aos conceitos que a leitura da Fenomenologia do Espírito, por meio de Kojève, virá ocupar. A formalização de uma negatividade parece ser, aqui, o ponto principal em torno do qual gira este processo.
\end{abstract}

Descritores: Psicanálise. Lacan, Jacques, 1901-1981. Hegel, Georg Wilhelm Friedrich, 1770-1831. Dialética.

E ste texto se estabelece a partir de um trajeto fundamental. Procuraremos elementos para sustentar que, mesmo antes da incidência dos elementos lógicos da linguística (e mais tarde da topologia) que permitiram a Lacan uma formalização mais estruturada na transmissão da psicanálise, ou seja, desde a tomada de contato com a clínica, o psiquiatra francês recém formado, já procurava centrar seus estudos e suas produções na relação que se estruturava entre médico e paciente, que lhe indicava sempre a dimensão do sujeito. De outra forma, o que se lança a partir da Tese de 1932 Da Psicose Paranóica e suas Relações com a Personalidade (Lacan, 1932/1975) é o projeto lacaniano de procurar estabelecer sua clínica pela implicação desse "sujeito falante, não o sujeito fictício da presença de si caro aos filósofos da consciência, mas o sujeito ativo da reivindicação, aquele que diz Je, Moi"

1 Psicanalista, membro do PROMUD - Programa de Atenção a Mulher Dependente Química do Instituto de Psiquiatria da Faculdade de Medicina da USP. R. Ovídeo Pires Campos, s/n. Cerqueira César. CEP 05403-010. Endereço eletrônico: ronaldo@csbr.com.br 
(Ogilvie, 1991, p. 17), esse mesmo sujeito desse "delírio (que) permanece incompreensível a um olhar organicista" (Ogilvie, 1991, p. 17).

O campo de investigação que se coloca através desse primeiro posicionamento apontará, por sua vez, como veremos, à já desenvolvida, à época, filosofia de Hegel e indicará o papel de grande ordem que esta ocupa nas primeiras formalizações lacanianas sobre sua clínica.

Procuraremos, então, ensaiar os caminhos deste trajeto que vai das discussões presentes em sua Tese à incidência de Hegel em seu pensamento, sempre buscando sublinhar a presença dos questionamentos clínicos que sustentam essa sua procura.

Mas como sabemos, o curso de Kojève (1979) Introdução à Leitura de Hegel, o qual Lacan passará a freqüentar assiduamente a partir de 1933, seu lugar primeiro e mais importante em direção a Hegel, é posterior à Tese na qual a problemática da clínica, ali psiquiátrica, já toma o centro de sua atenção.

Enredemos, portanto, a seguinte ordem: indicaremos o que se discute na Tese, seus encaminhamentos e, através das fendas que tais articulações suscitarão em Lacan, partiremos para sua tomada de Hegel que segue nos anos posteriores.

Porém, seria necessário, a título de evitar confusões, que não se tratará de estabelecer os diálogos entre Lacan e Hegel ao longo de todo ensino do primeiro. É notório que as articulações de Lacan com o autor da Fenomenologia do Espírito vão se desenvolvendo por releituras e modificações ao longo de todo o percurso. Aqui, falaremos apenas, brevemente, do primeiro contato.

\section{A tese (Aristóteles, Comte e Maurras)}

Na Tese, em que trabalha o Caso Aimé, percebe-se uma orientação clara em Lacan. Ao mesmo tempo em que se inscreve na tradição determinista e materialista que orienta o campo científico, tomando o fenômeno que 
se coloca à frente (o sujeito para Lacan) como algo apreensível sempre por meio de uma metodologia, afastando-se assim de qualquer fenomenologia de inspiração husserliana, Lacan não verá razão no abandono daquilo que entende como chave maior de compreensão sobre o paciente - seu pensamento, no caso de Aimé, delirante. Relegado pela psiquiatria organicista à categoria de epifenômeno, portanto rebaixado na cadeia causal como simples efeito e, assim, não determinável por outro caminho que não pela determinação de sua causa orgânica, a fala delirante, que revela o pensamento subjacente a ela, é resgatada por Lacan e colocada em lugar privilegiado para a correta abordagem do fenômeno que se coloca à frente do psiquiatra. Para o autor da Tese, a loucura é um fenômeno do pensamento e é neste campo da representação que deve ser buscada sua determinação.

Lacan denuncia o falso materialismo que envolve o discurso organicista.

\footnotetext{
A personalidade se manifesta, indiscutivelmente, através de uma série de sentimentos, de representações, de ações e de discursos que as designam. O fato de que não se possa prejulgar sua significação (e portanto sua verdade) nada extrai de sua presença (...) ser materialista não é relegá-la (a personalidade) ao esquecimento, mas pesquisar seu determinismo próprio. (Ogilvie, 1991, pp. 19-20)
}

No caso de uma paciente paranóica, que exibia toda riqueza do pensamento delirante, que a colocava em relação direta aos componentes de suas representações, buscar seu determinismo próprio era refutar qualquer abordagem normativa que entendesse tal manifestação como produto de um desajuste orgânico. Nesse sentido, o que já se desenhava em Lacan, era aquilo que já se desenhara em Freud, mesmo que de forma diversa: um caminho que vai da determinação do patológico à constituição do humano em geral.

Se o caminho repetido de Lacan em relação a Freud, citado acima, não pode ser tributado à intencionalidade do primeiro, não se pode dizer o mesmo a respeito da posição metodológica que Lacan assume para si. Encontramos, então, o jovem psiquiatra francês já bastante influenciado por Freud naquilo que irá sempre mais aproximá-los, o método psicanalítico. 
O mérito dessa nova disciplina, que é a psicanálise, é nos ter ensinado a conhecer essas leis, a saber: aquelas que definem a relação entre o sentido subjetivo de um fenômeno de consciência e o fenômeno objetivo a que corresponde - positivo, negativo, mediato ou imediato -, essa relação é com efeito, sempre determinada. Através do conhecimento dessas leis, pôde-se assim restituir seu valor objetivo, mesmo para esses fenômenos de consciência, em relação aos quais se havia assumido uma posição tão pouco científica ao desprezá-los , tais como os sonhos... ou ainda os atos falhos. (Lacan, 1932, citado por Ogilvie, 1991, p. 32)

Porém, se o método podia ser logo identificado à psicanálise freudiana, o trajeto teórico lacaniano se distinguirá do psicanalista austríaco nas respostas precisas que buscará encaminhar ao raciocínio substancialista, que impede que se chegue ao que mais define o ser humano. $\mathrm{O}$ percurso que Lacan adotará emprestará elementos de uma tradição que vem desde Aristóteles, passando por Comte e que é, mais extensamente, trabalhada em Maurras, autor bastante influente no primeiro Lacan. A personalidade, que não é redutível ao nível orgânico de funcionamento e que nem deve se render à noção de existência que a coroaria como fenômeno sem determinação, também ultrapassa a marca individualista/atomística de seu entendimento, na medida em que refere, necessariamente, às relações que se estabelecem entre o homem e seu meio e que o definem como um ser social.

Os fenômenos da personalidade são especificamente humanos, isto é, não se desenvolvem na dimensão única de um automatismo instintual, mas na dimensão plural de um comportamento acoplado a uma representação, e, enquanto tal, assumem sentido e funcionam num sistema social submetido a leis específicas. (Ogilvie, 1991, p. 28)

Tal antropologia, que passa a orientar os passos de Lacan, receberá forte empuxo do pensamento de Spinoza na articulação que se desenha entre o campo representacional (a personalidade), o organis mo (indivíduo) e o meio (social para o homem). Lacan indica o que chama de uma tendência concreta na qual "um fato mental pode ser apreendido no comportamento que é a sua expressão, contanto que se veja neste comportamento um ciclo completo correspondente a uma significação, portador de uma intencionalidade (consciente ou inconsciente)" que excede o indivíduo (Ogilvie, 1991, p. 59). Assim, o fenômeno mental não pode ser isolado como um objeto em 
si, ou como efeito de um corpo, ou como representação da vida mental de um indivíduo, mas remetido a um conjunto social, cuja articulação se dá pelo comportamento, que irá indicar sua significação ampla.

\begin{abstract}
Aparece sob a forma mental de um processo, em seu fundo mais geral. Será a manifestação de um processo físico, corporal? Não... enquanto corpo humano (...) é a manifestação de alguma coisa de muito mais complexo: a situação objetiva que faz com que os corpos humanos estejam presentes e sustentados na existência; a duração no tempo e o desenvolvimento no espaço, que seriam impensáveis se se considerasse o corpo isoladamente, separado das múltiplas relações sociais que, antes mesmo de lhe conferir uma configuração particular, permitem-lhe simplesmente estar presente. (Ogilvie, 1991, p. 60)
\end{abstract}

Tal paralelismo (fato psíquico-comportamento-sociedade), entendido como oposto de qualquer hierarquia causal, torna-se, na realidade, a categoria que será utilizada por Lacan para contrapor-se ao substancialismo, dando outra alternativa à explicação, fora do dualismo de propriedades. Na realidade, trata-se de um paralelismo que, ao apontar para uma só substância - o lugar irredutivelmente social do homem -, desfaz o próprio paralelo - idéia e corpo -, dando fim ao romance causal de domínio hierárquico.

No entanto, resta a Lacan, após este posicionamento claro que privilegia, antes de tudo, o discurso dos pacientes - que, como vimos, encaminha uma representação que deve ser colocada em primeiro plano -, resta dar conta desta descontinuidade que se observa entre o psicótico e aqueles de personalidade normal (conceito usado por Lacan). De fato, como psiquiatra, Lacan não se vê livre das questões pertencentes a sua seara: nosologia, etiologia e cura.

Aqui, parece que Lacan é novamente convocado, pelo raciocínio causal, a localizar a origem, o processo de anterioridade na definição que artic ula as categorias. Se, para ambos, psicose e personalidade normal, o que se opera é essa mesma condição irredutivelmente social, por outro lado, há de se estabelecer a diferença que as separa. Lacan seguirá por um trajeto, malabarístico de certa forma, tentando dar conta de todas as articulações que suas próprias afirmações suscitam. 
Lacan, buscando escapar ao debate entre o adquirido (determinismo ambientalista) e o inato (determinismo orgânico), construirá uma série causal heterodoxa (relações entre causa eficiente e causa primeira). O propósito maior dessas relações causais parece ser, exatamente, o continuísmo da lógica, que não atribui primazia causal alguma na determinação do sujeito e que o coloca em um meio de caminho. É isso que, aqui, se torna importante, afirmando três pontos primordiais: "o papel preponderante da atividade do sujeito e a dependência (desse sujeito) com relação a uma situação externa, à qual ele está articulado sob a forma negativa de uma reação" (Ogilvie, 1991, p. 87).

É neste cruzamento que devemos nos deter para compreender as fendas levantadas pela Tese, que buscarão resposta posterior na leitura kojeviana de Hegel. Entretanto, aqui, é como se já estivesse respondendo, de uma só vez (sem dar exatamente uma resposta que entre nesse lugar do simples "não"), por um lado, ao inatismo (e sua hereditariedade) e ao ambientalismo, enquanto determinações exógenas ao sujeito e, por outro, a toda filosofia da consciência, que centra sua especulação na consciência de si e na idéia de indivíduo. Isso porque - e essa parece ser a idéia clara que resta da Tese - o sujeito reage a algo, nele mesmo, que lhe é estranho, embora não perceba que o faça, e essa coisa à qual ele reage é a própria "outra coisa" que não ele mesmo, o seu ser social.

\section{Lacan e a clínica da dialética}

Zizek (1991) nos alerta, a título de ilustrar a idéia de razão para Hegel, que Kasper Hauser seria outra coisa se não se houvesse garantido a ele o lugar prévio o qual veio ocupar. Diz-nos que foi a exata discussão sobre os enlaces entre natureza e cultura na determinação do homem, querela fervente à época, que criou o objeto que viria entrar no debate: o Kasper. A razão para Hegel, segundo Zizek, indica, portanto, a apreensão desse lugar prévio vazio, dessa forma precedente ao seu objeto. Não se pode esconder a tendência deste texto em afirmar a possibilidade dessa lógica, pelo menos em relação a nosso projeto pretendido, pois, parecia estar, ao final da Tese de 
1932, montado este lugar anterior àquilo que lhe vem ao encontro, que seria, no final do ano seguinte, Hegel pelas mãos de Kojève.

Ora, é sabido que o trajeto da filosofia hegeliana se estabeleceu por meio de uma inversão decisiva naquilo que se efetuava na doutrina kantiana sobre o conhecimento. Se a revisão de Kant sobre o racionalismo de ordem cartesiana impunha-se como uma crítica, sua proposta de categorias a priori, centro dessa crítica, não incidia sobre a separação entre sujeito e objeto senão para efetivá-la ainda mais. Essa cisão entre sujeito/objeto indica o limite do saber que se coloca nessa relação. A ciência do mundo não se realiza como conhecimento absoluto, da coisa-em-si, inatingível na experiência com o objeto.

O idealismo, aqui, é claro em Kant. Na ciência do mundo, sempre se esbarraria com o fenômeno, que aponta o entendimento do objeto mas, no mesmo movimento, afasta a coisa-em-si. À razão (a razão prática), restaria esta liberdade "transempírica", desapegada dessa ciência do mundo (dos objetos), que revelaria aquilo que é incondicionado, absoluto. O que se observa é uma antinomia irredutível entre sujeito/objeto que afasta a razão, nesta relação, da produção da verdade. Essa contradição fixa e insolúvel cria um movimento mecânico, repetido em toda relação, anistórico e imutável, pressupondo categorias que mediatizam uma relação que não coloca o sujeito em questão (a consciência não é estranha a si mesma, mesmo que não conhecida). É neste par antinômico estabelecido na filosofia - contemplação/ação -, que representa a formalização de uma separação entre ciência e filosofia em Kant, é neste par que Hegel irá incidir.

É por uma certa reativação da ação, que encontrará sua chave para colocar a imutabilidade da relação sujeito/objeto kantiana em questão, trazendo a discussão sobre o sujeito (sua consciência) para a ordem do dia, tornando-a, a consciência, fenômeno, algo a ser construído no estabelecimento da relação de ação com o objeto. O que surge neste movimento é a interrogação sobre o próprio sujeito cognoscente, daí a tomada do Espírito como material para uma fenomenologia. "Ciência da experiência da consciência", num primeiro título de Hegel dado à obra. 
Hegel transfere para o próprio coração do sujeito - para o seu saber - a condição de fenômeno que Kant cingira à esfera do objeto. Essa é a originalidade da "Fenomenologia" e é nessa perspectiva que ela pode ser apresentada como processo de formação (Bildung) do sujeito para a ciência. (Lima Vaz, 2002, p. 15)

Alguns pontos daí já se desprendem para a compreensão de ter sido, o curso de Kojève, o Kasper-Hauser para Lacan. Além da evidente pertinência desse projeto hegeliano, essa "formação do sujeito para a ciência", para o psiquiatra francês e o fato de que se trata de uma lógica que postula um método que vai ao encontro da apreensão do sujeito, outros aspectos parecem se tornar ainda mais importantes para Lacan.

É a definição, em Hegel, desse sujeito através da relação com o objeto (posto como um outro, seu não-ser), que se revelará o solo desejado que as âncoras lançadas pela Tese (que se ocupava exatamente de colocar a determinação do sujeito sob um método) não haviam satisfatoriamente encontrado.

As características dessa relação guardam importância para as considerações da Tese, primeiro, porque expõe o sujeito ativo que Lacan havia apontado, a sua "estrutura reacional"; depois, porque permite entender outro conceito fundamental ali posto: a tal dependência do sujeito, esse fundo que faria deste um ser irredutivelmente social, passa a se apoiar na idéia hegeliana da negação. A consciência é constituída na apreensão de seu não-eu e pela transformação deste. Assim, não existe sujeito fora desta relação, porque na exceção da relação, o que existe é um espaço vazio, o nada. Para a fórmula da Tese teríamos a reformulação: o ser humano é um ser social na medida em que não é outra coisa.

Para além, nas figuras da fenomenologia, o sujeito ultrapassaria essa relação sensível, de apreensão do objeto, porque, sendo o humano consciente dessa oposição ao objeto, torna-se consciente-de-si (auto-consciência) como sendo-outro, um outro que também já não o é.

$\mathrm{Na}$ verdade, a consciência-de-si é reflexão a partir do ser do mundo sensível e do mundo da percepção e é, essencialmente, um retorno a partir do ser-outro (...) assim, o mundo sensível se desdobra no espaço dessa identidade, mas não mais como objeto que faz face à consciência, e sim como o ser que, para a consciência-de-si, é marcado como o caráter negativo e cujo em-si deve ser suprimido para que se 
constitua a identidade concreta da consciência consigo mesma. (Lima Vaz, 2002, p. 19)

É este movimento de caráter negativo em relação ao outro que Hegel tratará por desejo. A satisfação do desejo é a assimilação do outro, seu nãoser, na imediata transformação deste. Na ação kojeviana, o desejo destrói uma realidade objetiva para o satisfazer e cria, em seu lugar, por meio da própria destruição, a realidade subjetiva.

Indo além, Hegel marca a particularidade do desejo humano que, sendo consciência-de-si, nessa alteridade com o objeto, tem também consciência do outro (humano) como consciência de si, e buscará sua satisfação nesse encontro com esse outro que, de certa forma, é si mesmo. Kojève cunhará a expressão "o desejo é o desejo do outro". Nesse sentido, toda relação humana é com o desejo do outro, na medida em que, negativamente, nos constituímos nessa dialética.

A tomada de contato com esta lógica (de fato uma construção original no campo da filosofia) fará com que Lacan reposicione suas afirmações, sem, contanto, operar mudanças de foco sobre aquilo que se desprendia de sua clínica. Ao contrário, revela-se contribuição importante para que seguisse no caminho que a clínica indicava.

Lacan atinge, então, em cheio, o sujeito e sua problemática. Primeiramente por sua própria constituição, que descentra o "eu" por uma alteridade não externa ao sujeito. Só se diz "eu” (numa unificação imaginária, como se verá) porque há um "não-eu" no próprio sujeito, sendo este portanto, desde seu surgimento, dividido em si mesmo. Depois, porque essa instância que diz "eu" perde qualquer autonomia pelo fato mesmo de surgir de uma relação não determinada por ela, mas por algo anterior. Fica, então, aberto aí o espaço necessário para a suposição de algo estranho a esse "eu", pertencente ao sujeito, que o determina - na posterior reformulação do cogito cartesiano por Lacan: "penso onde não sou" e "sou onde não penso".

É essa lógica da negatividade que aproxima, também, definitivamente, a clínica de Lacan da psicanálise, não mais somente pela reafirmação de sua metodologia, mas também como lugar que empresta conceitos fundamentais 
para a compreensão do sujeito: a pulsão (termo, aliás, usado por Hegel antes de Freud), a identificação e a transferência.

O "Estágio do Espelho", de 1936, texto perdido duplamente, representará esta passagem em seu pensamento e inaugura um Lacan propriamente psicanalista, que privilegia o imaginário, e que centra a questão do sujeito na dialética do reconhecimento do desejo e do desejo de reconhecimento, como um círculo de alienação permanente do humano (numa aplicação bastante particular e bem distinta do fim que Hegel enxerga para essa dialética, entendendo-a como processo de construção de um saber último, absoluto).

Parece, no entanto, um passo de extrema importância dado por Lacan em relação à clínica psicanalítica: é uma hipótese que propomos. Lacan, reafirmando a determinação do sujeito, parece desobjetivizar sua causa, relativizando-a por uma subjetivação, naquilo que coloca o sujeito sempre diante de outro sujeito. Assim, passa de uma clínica (da psiquiatria organicista e psicologizante) que se estabelece entre um sujeito (o médico, seu saber) e um objeto (a doença, a disfunção) para uma outra que se estrutura pela relação entre sujeitos, cujo estatuto maior aponta para a dimensão do diálogo.

Torres, R. (2004). Lacan and Hegel. Psicologia USP, 15(1/2), 309-320.

\begin{abstract}
Jacques Lacan's approach to Hegelian philosophy was not by chance. The concrete tendency and reactive structure concepts described in his 1932 Thesis already set room to concepts that the reading of Phenomenology of Spirit through Kojève would occupy. The formalization of negativity in the individual's essence seems to be the core around which this process gravitates.

Index terms: Psychoanalysis. Lacan, Jacques, 1901-1981. Hegel, Georg Wilhelm Friedrich, 1770-1831. Dialectic.
\end{abstract}




\section{Lacan e Hegel}

Torres, R. (2004). Lacan et Hegel. Psicologia USP, 15(1/2), 309-320.

Résumé: Jacques Lacan ne s'est pas approché de la philosophie par hasard. Les idées de tendance concrète et de structure réactionnelle qu'on trouve sur sa thèse de 1932, signalaient déjà les lieux préalables aux concepts que la lecture de la Phénoménologie de l'Esprit, à travers Kojève, ocuppera. La formalisation d'une négativité semble être l'axe de ce processus.

Mots-clés: Psychanalyse. Lacan, Jacques, 1901-1981. Hegel, Georg Wilhelm. Friedrich, 1770-1831. Dialectique.

\section{Referências}

Arantes, P. E. (1991). Um Hegel errado mas vivo. IDE, (21). 72-79.

Arantes, P. E. (1992). Hegel no espelho do Dr. Lacan. IDE, (22), 64-77.

Garcia-Roza, L. A. (1987). Freud e o inconsciente. Rio de Janeiro: Jorge Zahar.

Hegel, G. W. F. (2002). Fenomenologia do espírito. Petrópolis, RJ: Vozes.

Hondt, J. (1981). Hegel. Lisboa, Portugal: Ed. 70.

Juranville, A. (1987). Lacan e a filosofia. Rio de Janeiro: Jorge Zahar.

Kojève, A. (1978). Introduction à la lecture de Hegel. Paris: Gallimard.

Lacan, J. (1975). De la psychose paranö̈aque dans ses rapports avec la personnalité: suivi de premiers écrits sur la paranö̈a. Paris: Seuil. (Original apresentado como tese em 1932)

Lacan, J. (1985). O seminário. Livro 11: Os quatro conceitos fundamentais da psicanálise. Rio de Janeiro: Jorge Zahar. (Trabalho original publicado em 1964)

Lacan, J. (1998). Escritos. Rio de Janeiro: Jorge Zahar.

Lacan, J. (1998). O estágio do espelho como formador da função do eu. In J. Lacan, Escritos. (pp. 96-103). Rio de Janeiro: Jorge Zahar. (Trabalho original publicado em 1936)

Lacan, J. (1999). O seminário. Livro 5: As formações do inconsciente. Rio de Janeiro: Jorge Zahar. (Trabalho original publicado em 1957-1958)

Lima Vaz, C. L. (1981). O senhor e o escravo: Uma parábola da filosofia ocidental. Sintese, (8), 21, 7-29. 


\section{Ronaldo Torres}

Lima Vaz, C. H. (2002). A significação da fenomenologia do espírito. In G. W. F. Hegel, Fenomenologia do espírito (pp. 9-19). Petrópolis, RJ: Vozes.

Milner, J.-C. (1996). A obra clara - Lacan, a ciência, a filosofia. Rio de Janeiro: Jorge Zahar.

Ogilvie, B. (1991). Lacan: A formação do conceito de sujeito. Rio de Janeiro: Jorge Zahar.

Roudinesco, E. (1994). Jacques Lacan. São Paulo: Companhia das Letras.

Zizek, S. (1991). O mais sublime dos histéricos - Hegel com Lacan. Rio de Janeiro: Jorge Zahar.

Recebido em 09.09.2004

Aceito em 17.11.2004 